\title{
Keine Angst vor der Katarakt
}

\section{Ob Patienten mit atopischer Dermatitis durch Anwendung topischer Glukokortikoide im Periorbitalbereich ein erhöhtes Risiko für Glaukom und Katarakt haben, ist nicht zweifelsfrei klar. Eine retrospektive Analyse liefert Daten für die Diskussion.}

$\mathrm{D}$ ass glukokortikoidhaltige Augentropfen oder periokuläre Glukokortikoid-Injektionen Glaukome und Katarakte hervorrufen können, ist un-

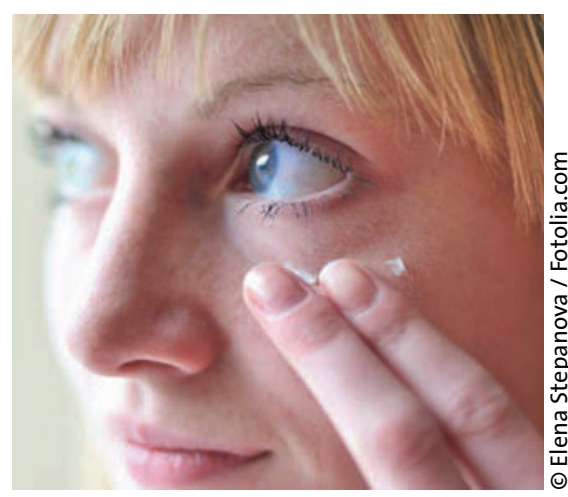

Die Anwendung von topischen Glukokortikoiden im Augenbereich zur Behandlung einer atopischen Dermatitis ist offenbar sicherer als angenommen. bestritten. Bei Patienten mit atopischer Dermatitis findet man häufiger Katarakte, meist sind diese aber mit der atopischen Erkrankung selbst assoziiert. 88 Patienten der Universitätsklinik Utrecht, Niederlande, die von atopischer Dermatitis betroffen waren, wurden deshalb in einem Interview nach einem Befall von Augenlidern und periorbitaler Haut gefragt, der Glukokortikoidverbrauch anhand der Verordnungsakten abgeschätzt und die Patienten ophthalmologisch untersucht.

Von den 88 Patienten mit einem Durchschnittsalter von 37,2 Jahren verwendeten 37 Patienten topische Glukokortikoide der Klassen III und IV auf Augenlidern und in der Periorbitalregion durchschnittlich an 3,9 Tagen pro Woche in 6,4 Monaten pro Jahr über 4,8 Jahre. Nur einer der der 88
Patienten hatte einen vorübergehenden Anstieg des Augeninnendrucks und ein Patient einen veränderten blinden Fleck, allerdings ohne glaukomatöse Defekte im Sehfeld. Die Diagnose Katarakt wurde bei sieben Patienten gestellt: In zwei Fällen war die Schädigung glukokortikoidinduziert, in einem weiteren atopieassoziiert und bei vier Patienten lagen altersbedingte Katarakte vor. Die glukokortikoidinduzierten Katarakte wurden aber auf die Einnahme systemischer Glukokortikoide allein oder zusätzlich zur topischen Applikation zurückgeführt.

Fazit: In einer Studie mit retrospektiv erhobenen Daten zu Glukokortikoidverbrauch und -applikationsform ergab sich kein Zusammenhang zwischen der topischen Applikation von Glukokortikoiden auf Augenlider und periorbitale Haut und dem Auftreten von Katarakt und Glaukom. Barbara Kreutzkamp

Haeck IM et al. Topical corticosteroids in atopic dermatitis and the risk of glaucoma and cataracts. J Am Acad Dermatol 2011; 64: 275-81

\section{Allergisch trotz Immunsuppression - warum?}

\section{Warum reagieren Patienten unter Immunsuppressiva nach Organ- transplantation immer noch allergisch? Eine In-vitro-Untersuchung an Blutmonozyten ging den immunologischen Ursachen auf zellulärer Ebene nach.}

P atienten nach Organtransplantationen erhalten immunsupprimierende Medikamente, welche die zelluläre Immunantwort blockieren. Trotzdem ist bei diesen Patienten die Rate von IgEvermittelten Sensibilisierungen und allergischen Symptomen nicht niedriger als in der Normalbevölkerung. Möglicherweise unterdrücken die Immunsuppressiva eher die TH1- als die TH2-ZellAntworten, so dass sich eine TH2-Verschiebung einstellt. Außerdem könnten durch die Calcineurin-Inhibition die regulatorischen T-Zellen (Treg) herunterreguliert werden, wodurch die allergen- spezifischen Effektorzellen nicht mehr ausreichend kontrolliert werden. Um einen besseren Einblick in die zellulären Mechanismen der Wirkung von Immunsuppressiva auf die allergenspezifische Immunantwort zu erhalten, untersuchten österreichische Forscher die Immunantwort von 65 Allergiepatienten, die nach einer Transplantation unter Immunsuppressiva standen. Die peripheren mononukleären Blutzellen wurden in vitro einem allergenspezifischen Proliferationstest, einer Real-time-PCR zum Nachweis der beiden regulatorischen Zytokine Interleukin-10 und „transforming growth factor- $\beta$ “ (TGF- $\beta$ ) sowie des Treg-assoziierten Transkriptionsfaktors „forkhead box P3“ (FOXP3) unterzogen. Zudem wurden sie Treg-Inhibitions- und Depletionsassays untersucht.

Es zeigte sich, dass die allergenspezifische Proliferation unter der Immunsuppression nicht gehemmt wurde, obwohl die T-Zellantworten stark supprimiert waren. Dies ist vermutlich auf eine gleichzeitige Suppression des TregKompartiments zurückzuführen.

Fazit: Transplantatpatienten reagieren auch unter Immunsuppression noch auf Allergene. Der Grund dafür könnte eine unzureichende Kontrolle durch die regulatorischen T-Zellen sein, die durch die Immunsuppressiva ebenfalls herabreguliert werden. Barbara Kreutzkamp

Eiwegger T et al. Impact of systemic immuno-suppression after solid organ transplantation on allergen-specific responses. Allergy 2011; 66: 271-8 